\title{
A PCR-based Assay for Distinguishing between A1 and A2 Mating Types of Phytophthora capsici
}

\author{
Ping Li and Dong Liu \\ College of Plant Protection, Anhui Agricultural University, 130 West of Changjiang Road, Hefei \\ 230036, Anhui, China; and Department of Horticulture and Landscape, Anqing Vocational and \\ Technical College, 99 North of Tianzhushan Road, Anqing 246003, Anhui, China
}

Min Guo, Yuemin Pan, Fangxin Chen, Huajian Zhang, and Zhimou Gao ${ }^{1}$

College of Plant Protection, Anhui Agricultural University, 130 West of Changjiang Road, Hefei 230036, Anhui, China

\begin{abstract}
AdDITIONAL INDEX wORDs. pepper blight, molecular marker, genetic diversity, ISSR
Abstract. Sexual reproduction in the plant parasite Phytophthora capsici Leonian requires the interaction of two distinct mating types, A1 and A2. Co-occurrence of these mating types can enhance the genetic diversity of $P$. capsici and alter its virulence or resistance characteristics. Using an intersimple sequence repeat (ISSR) screen of microsatellite diversity, we identified, cloned, and sequenced a novel 1121-base pair (bp) fragment specific to the A1 mating type of $P$. capsici. Primers Pcap-1 and Pcap-2 were designed from this DNA fragment to specifically detect the A1 mating type. Polymerase chain reaction (PCR) using these primers amplified an expected 997-bp fragment from known A1 mating types, but yielded a 508-bp fragment from known A2 mating types. This PCR-based assay could be adapted to accurately and rapidly detect the co-occurrence of A1 and A2 P. capsici mating types from field material.
\end{abstract}

The oomycete plant pathogen, Phytophthora capsici, first described by Leon H. Leonian at the New Mexico Agricultural Research Station, is distributed globally and is a critical threat to vegetable production as a cause of damping-off, foliar blight, and fruit rot in solanaceous and cucurbitaceous plants (Babadoost, 2000; Erwin and Ribeiro, 1996; Granke et al., 2012; Hausbeck and Lamour, 2004; Leonian, 1922). The host range of this pathogen subsequently was expanded to include lima bean (Phaseolus lunatus L.), snap bean (Phaseolus vulgaris L.), fraser fir [Abies fraseri (Pursh) Poir.], and certain weeds (Davidson et al., 2002; Gevens et al., 2008; QuesadaOcampo et al., 2009).

As a heterothallic species, $P$. capsici requires crossfertilization by distinct mating types, A1 and A2, to complete the sexual stage of its life cycle (Savage et al., 1968). Coculture of the A1 and A2 types yields oospores, sexual spores that function in nature as the overwintering inoculum of the pathogen. Co-occurring A1 and A2 isolates of P. capsici were detected in New Jersey in 1981 and in North Carolina in 1990; the mating types have been identified in single-crop fields as well as within the same plant (Papavizas et al., 1981; Ristaino, 1990). Sexual reproduction augments genetic variation in $P$. capsici via allelic recombination. The resulting offspring genotypes may include acquired resistance to fungicides or antibiotics, creating new challenges for phytophthora blight management.

The genetic basis of mating-type establishment in oomycetes remains unclear. The mating types of ascomycetes and

Received for publication 17 Jan. 2017. Accepted for publication 16 May 2017. Funding was provided by the National Science Foundation Projects (Grant No. 31671977), Anhui Excellent Young Talents Support Plan Key Project (Grant No. gyxqZD2016516), and Anhui Natural Science Research Project (Grant No. KJ2015A368). Special thanks to Dr. Yuanchao Wang for providing the standard isolates.

${ }^{1}$ Corresponding author. E-mail: gaozhimou@126.com. basidiomycetes are expressed in a haploid life stage (Kües and Casselton, 1992). In contrast, oomycetes such as P. capsici are diploid during the vegetative stage, and mating-type alleles likely are inherited from distinct A1 and A2 parents in a heterozygous pattern. Therefore, a genetic marker for differentiating A1 and A2 mating types in $P$. capsici has been the subject of much speculation. A paucity of morphological and biochemical mutants has impeded genetic studies of $P$. capsici and other oomycetes (Judelson, 1996b). Phytophthora infestans (Mont.) de Bary has been used to address the genetic mechanisms of heterothallism in diploid fungi because its mating system is representative of most heterothallic oomycetes (Judelson, 1996a). In this species, mating type is determined by a single locus that displays a non-Mendelian pattern of segregation (Judelson et al., 1995).

Sexual reproduction is essential to the biology and epidemiology of $P$. capsici. Populations of $P$. capsici containing both A1 and A2 mating types can complete the sexual life stage to produce oospores with enhanced genetic variation and potentially higher virulence and adaptive resistance to fungicides (Parra and Ristaino, 2001; Qi et al., 2012; Satour and Butler, 1968). A rapid and facile genetic technique to evaluate the occurrence of $P$. capsici mating types in the field has implications for disease management. Intersimple sequence repeat fingerprinting (Zietkiewicz et al., 1994) is a simple and reliable assay to measure microsatellite (i.e., simple sequence repeat) frequency and infer genetic diversity (Blair et al., 1999). We applied ISSR fingerprinting to identify a genetic marker capable of distinguishing between $\mathrm{A} 1$ and A2 P. capsici mating types.

\section{Materials and Methods}

STRains AND Mycelium PReParation. Twenty-one $P$. capsici isolates were collected from infected peppers (Capsicum 
annuum L.) at different locations in Anhui, China, including Huainan, Hefei, Chaohu, Qianshan, Yuexi, Chizhou, Tongling, Fuyang, and Yingshang. Standard isolates with known mating types, P991 (A1) and P731 (A2), were kindly provided by Y.C. Wang of Nanjing Agricultural University, Nanjing, China (Table 1). All cultures were obtained from single zoospores (Ko, 1981). Twenty-three pieces of agar culture obtained from the advancing margin of a 3-d-old colony growing on a plate of carrot agar were inoculated into liquid Plich medium $(0.5 \mathrm{~g}$ $\mathrm{KH}_{2} \mathrm{PO}_{4}, 0.25 \mathrm{~g} \mathrm{MgSO} \cdot 7 \mathrm{H}_{2} \mathrm{O}, 1 \mathrm{~g}$ asparagine, $1 \mathrm{mg}$ thiamine, $0.5 \mathrm{~g}$ yeast extract, and $25 \mathrm{~g}$ glucose in $1000 \mathrm{~mL}$ distilled water). After incubation at $25^{\circ} \mathrm{C}$ on an orbital shaker at $100 \mathrm{rpm}$ (THZ-300; Yiheng Co., Shanghai, China) for $\approx 7 \mathrm{~d}$, mycelia were harvested by filtration through a sterile filter (Miracloth; Zhongfang Co., Nantong, China) and stored at $-20^{\circ} \mathrm{C}$ before DNA preparation.

Conventional mating-TyPe Determination. The mating types of the 21 isolates were determined by pairing with known A1 isolate (P991) and A2 isolate (P731) on a petri dish $(9 \mathrm{~cm}$ diameter) containing 10\% clarified V8 medium (Ko, 1981), respectively. A plug of an isolate to be tested was placed on one side of the plate with a plug of the A1 or A2 standard isolate on the opposite side. The plates were incubated at $25^{\circ} \mathrm{C}$ in the dark for $14 \mathrm{~d}$. Then, the formation of oospores was examined under a binocular microscope at 100-fold magnification (CC23; Olympus Corp., Tokyo, Japan).

Extraction of GENOMic DNA. Total genomic DNA was extracted from each isolate as described previously (Wang and Zheng, 2003) with the following modifications: the air-dried pellet was resuspended in $100 \mu \mathrm{L}$ Tris-EDTA (TE) buffer [10 mm Tris-HCl (pH 7.4), 1 mm EDTA] and $2 \mu \mathrm{L}$ RNase (10 $\left.\mathrm{mg} \cdot \mathrm{mL}^{-1}\right)$. Samples were then incubated at $37^{\circ} \mathrm{C}$ for $1 \mathrm{~h}$. DNA was quantified using a spectrophotometer (Nanodrop
N.D.1000; Thermo Fisher Scientific, Wilmington, DE), and it was diluted to $50 \mathrm{ng} \cdot \mu \mathrm{L}^{-1}$ with TE buffer and then stored at $4{ }^{\circ} \mathrm{C}$.

ISSR ANALYSIS. ISSR fingerprinting was performed using 40 different primers (Sangon Biotechnology Co., Shanghai, China) on isolates of different mating types and pathogenicity. Twenty-three isolates were selected (Table 1). A $25-\mu \mathrm{L}$ reaction mixture consisting of $2.5 \mu \mathrm{L} \mathrm{10X} \mathrm{PCR} \mathrm{buffer,} 200 \mu \mathrm{M}$ dNTPs, $0.2 \mu \mathrm{M}$ primer, $0.5 \mu \mathrm{L}$ template DNA, and $1.25 \mathrm{U}$ Taq DNA polymerase (Takara Bio, Dalian, China) was subjected to thermal cycling in a thermal cycler (C1000; Bio-Rad, Hercules, CA). Thermal cycling parameters were as follows: initial denaturation at $94{ }^{\circ} \mathrm{C}$ for $5 \mathrm{~min}, 35$ cycles of denaturation at $94{ }^{\circ} \mathrm{C}$ for $1 \mathrm{~min}$, annealing at a primer-optimized temperature $\left(48-50{ }^{\circ} \mathrm{C}\right.$ ) for $1 \mathrm{~min}$, extension at $72{ }^{\circ} \mathrm{C}$ for $2 \mathrm{~min}$, and final extension at $72{ }^{\circ} \mathrm{C}$ for $10 \mathrm{~min}$. PCR products were electrophoresed through $1.8 \%$ agarose gels containing ethidium bromide in 10X Tris-borate-EDTA (TBE) buffer. Samples were visualized under ultraviolet illumination.

Cloning and Sequencing of SPecific DNA fragments. Before cloning, amplification products were excised and purified using an AxyPrep DNA Gel Extraction Kit, according to the manufacturer's instructions (Axygen Bioscience, Union City, CA). Purified PCR products were ligated into pMD18-T Simple Vectors (Takara Bio) and were transferred into Escherichia coli (Migula) Castellani and Chalmers according to the supplier's instructions. The clone specific to FY2 isolate was sequenced (Sangon Biotechnology Co.).

SYNTHESIS OF PRIMERS FOR DISTINGUISHING MATING TYPES OF P. CAPSICI. Based on the sequence of a specific 1121-bp fragment from the FY2 isolate, forward and reverse primers that probably distinguish between A1 and A2 isolates were designed using Primer Premier version 5.0 (Premier Biosoft, Palo Alto, CA). A $25-\mu \mathrm{L}$ reaction mixture was prepared consisting of $20 \mathrm{ng}$ genomic DNA, $2.5 \mu \mathrm{L} 10 \mathrm{X}$ PCR buffer, $200 \mu \mathrm{M}$ dNTPs, $0.1 \mu \mathrm{M}$ Table 1. Collection location in China, collection years, hosts, and mating types of the Phytophthor capsici isolates used in this study.

\begin{tabular}{|c|c|c|c|c|}
\hline Isolate no. & Location & Yr of collection & Host & Mating type \\
\hline HN1 & Huainan & 2006 & Capsicum frutescens L. & $\mathrm{A} 1$ \\
\hline $\mathrm{HN} 2$ & Huainan & 2006 & C. frutescens & A2 \\
\hline $\mathrm{HN} 3$ & Huainan & 2006 & C. frutescens & A1 \\
\hline HN4 & Huainan & 2006 & C. frutescens & A2 \\
\hline HN5 & Huainan & 2006 & C. frutescens & A2 \\
\hline HF2 & Hefei & 2007 & C. frutescens & A2 \\
\hline HF3 & Hefei & 2007 & C. frutescens & A2 \\
\hline HF5 & Hefei & 2007 & C. frutescens & A1 \\
\hline $\mathrm{CH} 1$ & Chaohu & 2009 & C. frutescens & A2 \\
\hline $\mathrm{CH} 2$ & Chaohu & 2009 & C. frutescens & A2 \\
\hline $\mathrm{CH} 4$ & Chaohu & 2009 & C. frutescens & A1 \\
\hline QS1 & Qianshan & 2008 & C. frutescens & A2 \\
\hline QS2 & Qianshan & 2008 & C. frutescens & A2 \\
\hline YX1 & Yuexi & 2008 & C. frutescens & A2 \\
\hline YX2 & Yuexi & 2008 & C. frutescens & $\mathrm{A} 2$ \\
\hline $\mathrm{CZ1}$ & Chizhou & 2009 & C. frutescens & A2 \\
\hline $\mathrm{CZ2}$ & Chizhou & 2009 & C. frutescens & A2 \\
\hline TL1 & Tongling & 2010 & C. frutescens & A2 \\
\hline FY2 & Fuyang & 2009 & C. frutescens & A1 \\
\hline YS1 & Yingshang & 2009 & C. frutescens & A1 \\
\hline YS2 & Yingshang & 2009 & C. frutescens & A1 \\
\hline P991 & - & - & - & A1 \\
\hline P731 & - & - & - & A2 \\
\hline
\end{tabular}
each forward and reverse primers, and $1.25 \mathrm{U}$ Taq DNA polymerase (Takara Bio). The following PCR profile was used as follows: initial denaturation at $94{ }^{\circ} \mathrm{C}$ for $5 \mathrm{~min}, 30$ cycles of denaturation at $94^{\circ} \mathrm{C}$ for $30 \mathrm{~s}$, annealing at $54{ }^{\circ} \mathrm{C}$ for $30 \mathrm{~s}$, extension at $72{ }^{\circ} \mathrm{C}$ for $1 \mathrm{~min}$, and final extension at $72{ }^{\circ} \mathrm{C}$ for $10 \mathrm{~min}$. PCR products were electrophoresed through $1.0 \%$ agarose gels containing ethidium bromide in 10X TBE buffer. Samples were visualized under ultraviolet illumination.

Determination MATING TYPE OF $\boldsymbol{P}$. CAPSICI IN FIELD MATERIALS BY PCR. For detection of the mating type in infected field plants, 1-month-old susceptible cultivar Bianjiao NO.1 (Fengle Seed Co., Hefei, China) was inoculated with four isolates of $P$. capsici Mat-A1 and 7 isolates of Mat-A2 by applying mycelium block stem wound inoculation. Inoculated seedlings were incubated at $25^{\circ} \mathrm{C}$ and 
$100 \%$ humidity for $12 \mathrm{~h}$ and then the genomic DNAs were extracted from infected pepper stems according to Silvar et al. (2005). DNAs from infected pepper plants showing symptoms and healthy plant were amplified using Pcap-1/Pcap-2 primer pair set according to the PCR protocol described previously.

\section{Results}

Mating-TyPe FReQuencies. Twenty-one isolates of $P$. capsici from Anhui province (China) were paired with isolates P991 (A1) and P731 (A2) to determine mating type. If oospores were produced from an A1 pairing, then the unknown isolate was designated A2; if the A2 pairing yielded oospores, the isolate was designated A1. Of the 21 isolates, 7 were A1 and 14 were A2 (Table 1).

MATING-TYPE-SPECIFIC ISSR MARKER. Genomic DNAs were extracted from 23 isolates of $P$. capsici. Forty ISSR primers were then screened to identify candidates that could distinguish between $P$. capsici mating types. Primer UBC821 (5'-GTGTGTGTGTGTGTGTT-3') reliably generated an 1121-bp fragment specific to the A1 mating type at a primeroptimized annealing temperature of $48{ }^{\circ} \mathrm{C}$ (Fig. 1). This fragment was further investigated for the development of a specific biomarker assay to distinguish between A1 and A2 isolates.

Cloning and Sequencing of the $P$. CAPSiCI A1-SPECIFIC FRAGMENT. The 1121-bp A1-specific DNA fragment was isolated, ligated into a T-vector, and transformed into $E$. coli. The cloned DNA was then sequenced using a T-vector universal

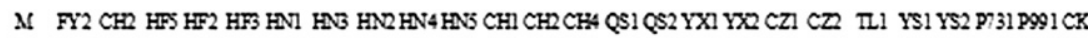

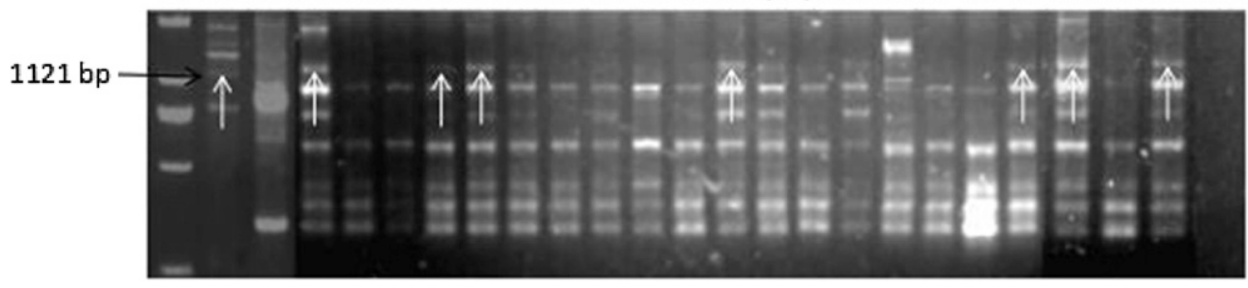

Fig. 1. Intersimple sequence repeat (ISSR) fingerprints of Phytophthora capsici generated using primer UBC821. The black arrow indicates the 1121-bp genomic DNA fragment derived from the A1 mating type. The white arrows indicate the specific ISSR product (1121 bp) derived from $P$. capsici Mat-A1 (lane M=DL 2000 marker, lane $\mathrm{CK}=$ no DNA template).

1 GARARTTGG CATGATTACG CCABGCTTGC ATGCCTGCAG GTCGACGATG TGTGTGTGTG TGTGTTCGAT TCACAGARAC 81 AATTGTGCAG AGGGAGGASA GATCGCARAT CCATTCGACA GABABCGAG BCGAGTGCTT GG]GTCAGAS CGAGTATTCG 161 GCGGCGATAC GCAGGTCATT TGACTGACAG GCACTARATG CGGGGGTGGT CECPTTTTTCTC TGGACGCACG CARARAGCTG 241 TTTCTTGGTA CTCGAGCTTT TAGAGGARTG CTTTTCTTGA AACCCATACT AGTGGTGTTA TGCTTTCGTT GTATAACTGT

321 GGATCCARAT CTTTCCTACA GCTASTCACC GCCCTGATAT GCACCAATTA TTTTTTGGCT GTCAGTAATG CCGATGCATT

401 ATTGGCTACT GCAACCGACT GGTAGTATCT GCACTAGTTG CAATGGGATG CAGACTACCT CCCTCTGCAC AATTGTTTCT

481 GTGAATCGAS CACACTAASG CGCGATCGCG TCCGCTCGAS AATGCTTGTT CCCTCGTTCA GASTGCTTTG TCACACCARA

561 ACGTCGAGGA TCAGABGGG GCAGTGAGCA CTGTTCATTG TTCAAGATGC GAACCABATC ATTGITTTTC TCCTTCACTG 641 GGTATCTTTT CABGCTGAST CATITTTGCG CCCATAGTGG CCGCGTGATT TACCACTAGG AGGTGITTIT TTCTAGATGT

721 CTGCGGCGAG CGTTGGCGTG AGGTTTTGCC GTGATGGTGG AGTGTATTCT TTCCCGGGAG ACTTCCAGIT GTATCGAGGA 801 GAABGGCGCT GTAGGCGASA TGACCCCCAG GGCCATCATT GGTGGTGGAT GTAGCCGTGG CAGTGTGGTG GTABGTTGGC 881 CTCATTTCTT TAATTGAAGG GTAGTATGCA GAGTGGTGGT GTTATGAGTG TTCGTTGGGT GTGATTTGTG TGTTGTGGTT 961 ACTTGATGGT GTGARAATTG TGTGAGTGTG TGTTGAARGT TACGCCTGTG TGGCTCAGTG GTAGAGCATC TGTCTTGTAA 1041 ACAGAAGGTC CCCGGTTCAS TCCCGGGCGG AGGCATGCCT TTTCACTGCT TGCATCTGTA COCTCTCTGT CTCGAGACTC 1121 回

Fig. 2. Nucleotide sequence of the Phytophthora capsici A1-specific DNA fragment. The numbers on the left refer to the nucleotide sequence. Boxes identify the forward (Pcap-1) and reverse (Pcap-2) primers used to differentiate P. capsici A1 and A2. primer pair (Fig. 2). The sequence was searched against

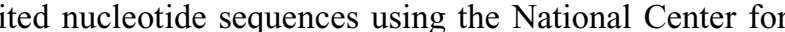
.

A PCR ASSAY OF MATING-TYPE IN P. CAPSICI. A PCR primer pair was designed from the 1121-bp A1-specific sequence to differentiate between $P$. capsici mating types. The sequence of ( The sequence of the reverse primer was fragment was specifically amplified from all A1 (y)es, whereas a 508-bp fragment was only amplified from A2

ANAlysis OF SPECIFIC SEQUENCE OF MATING TYPE OF A1 AND A2 isolates. The clones specific to isolates YS1, CH2, and TL1 were excised, purified, and sequenced. Then, sequences of

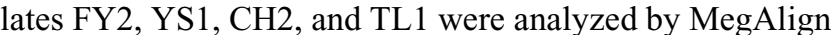
ific fragment between $\mathrm{A} 1$ and $\mathrm{A} 2$ mating types revealed higher homologous region, with bases insertion, deletion, or substitution.

DETERMination OF MATING TYPE OF $\boldsymbol{P}$. CAPSICI IN FIELD PLANTS. In this study, DNA obtained from the target $P$. capsici (Mat-A1 and Mat-A2) infected stems and health plants was amplified by PCR with the primer set Pcap-1/Pcap-2. Consequently, the predicted fragment of 997 and 508 bp was observed in stems from four isolates of A1 mating type and seven isolates of A2 mating type, whereas no amplification products were obtained for samples that were healthy (Fig. 5). Therefore, the use of the primer pair set will make it possible to quickly diagnose the mating type of $P$. capsici isolates in field material of the pepper blight.

\section{Discussion}

P. capsici is a soilborne plant pathogen of global significance, particularly with regard to vegetable crops. Because $P$. capsici requires cross-fertilization between disparate $\mathrm{A} 1$ and $\mathrm{A} 2$ mating types to sexually reproduce and enhance its genetic diversity, the virulence and resistance characteristics of this 


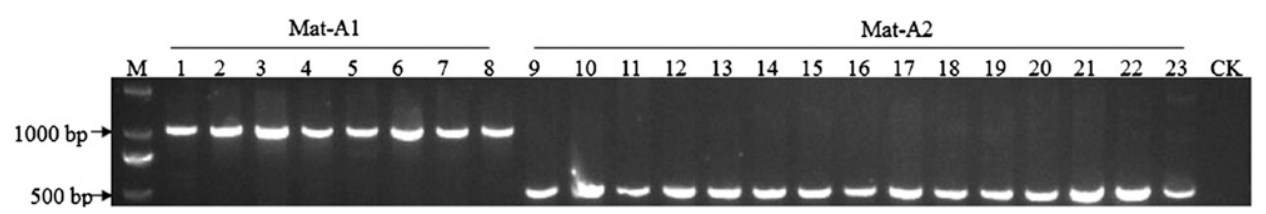

Fig. 3. Polymerase chain reaction profiles demonstrating mating type determination of Phytophthora capsici isolates using Pacp-1/Pcap-2 primers. Lane M, DL 2000 marker; lanes 1-8, P. capsici A1; lanes 9-23, P. capsici A2 (lane $\mathrm{CK}=$ no DNA template). Isolates of $P$. capsici are listed in Table 1 .

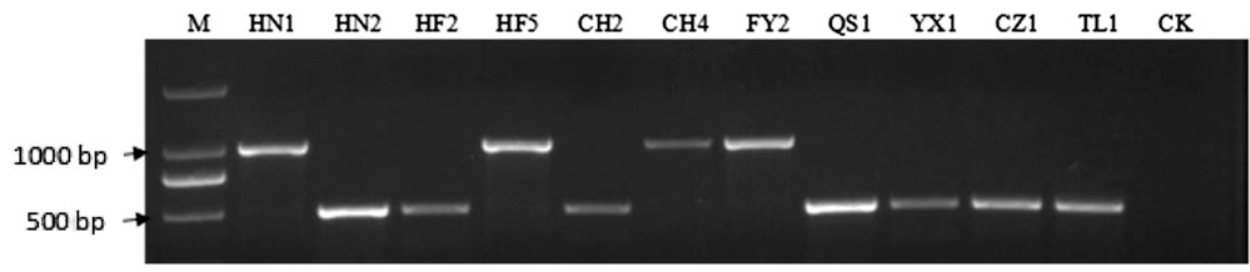

Fig. 4. Alignment of mating-type-specific sequences corresponding to different isolates of Phytophthora capsici including FY2, YS1, CH2, and TL1. Shade residues with solid black represent them match the consensus exactly. Dashed lines indicate absence of sequence. Numbers on the right refer to the nucleotide sequences.

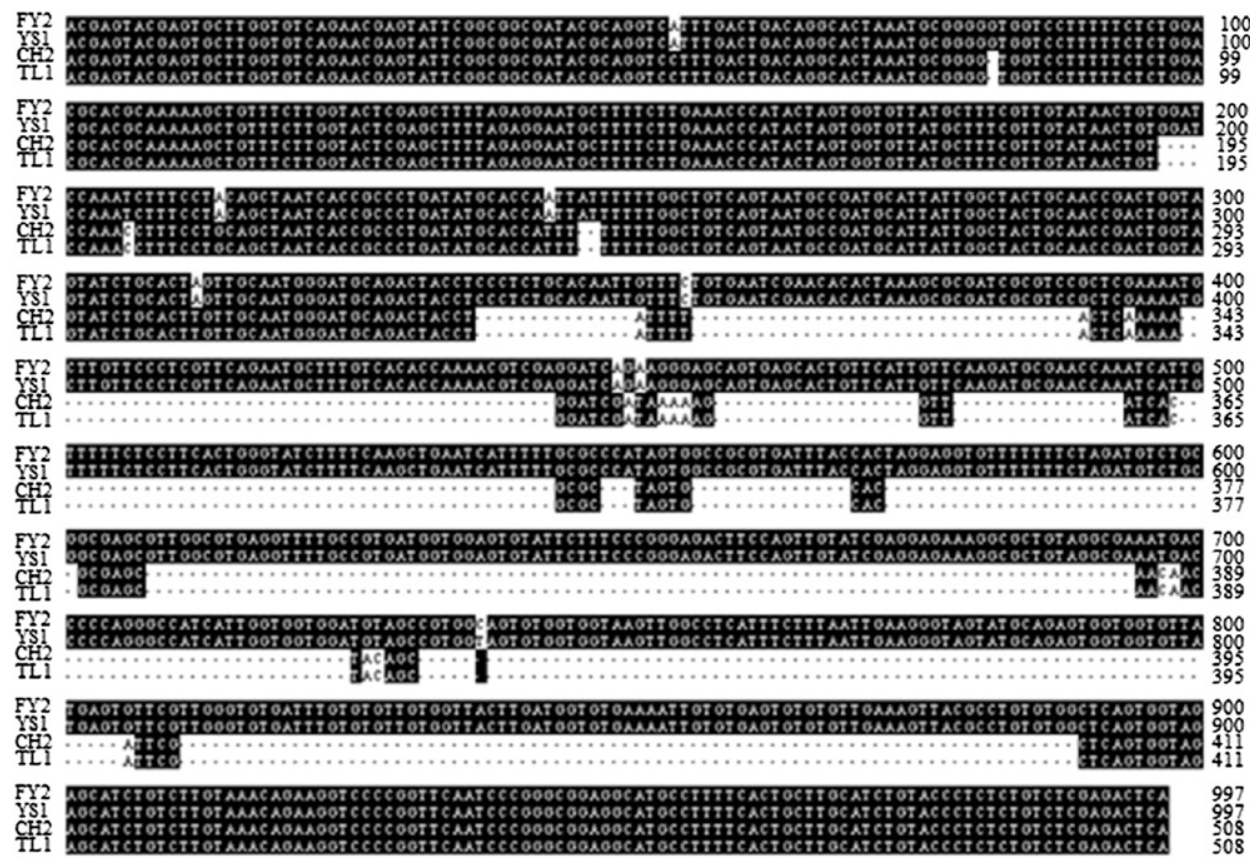

Fig. 5. Mating type determination of Phytophthora capsici in artificially infected plants using Pacp-1/Pcap-2 primers (lane $\mathrm{M}=$ DL 2000 marker, lanes 1-11 = artificially infected plants, lane CK = no DNA template). Isolates of $P$. capsici are listed in Table 1.

pathogen depend on the geographical codistribution of its mating types. We sought to develop an accurate and rapid assay to identify $P$. capsici mating types in the field and prevent substantial crop losses from this pathogen. Traditional matingtype assays include visual examination of pheromone production (Ko, 1988) and attempted cross-fertilization with known mating types. These methods are time-consuming and may require microscopic observation. Furthermore, this mating test often failed because the mating type of $P$. capsici could change in response to mechanical damage, growth condition, and the like (Zheng, 1997). The availability of an improved method for the rapid and accurate determination of mating type of $P$. capsici becomes very important. Various PCR-based molecular methods have been developed to detect and differentiate among fungal plant pathogens using minute quantities of DNA and minimal handling times (Lacourt and Duncan, 1997; Schena et al., 2002). Although molecular detection of different mating types had been reported for $P$. infestans (Kim and Lee, 2002; Kim et al., 2005), no such methodology was available for $P$. capsici. In this study, in contrast to traditional mating-type determination, a PCR-based assay is easily used to detect mating types in vitro and in planta even before they develop typical symptoms. Also, further studies are needed to test the sensitivity of the primer pair linked to Mat-A1 and Mat-A2 of P. capsici in the soil before infecting peppers.

Using a primer set designed against an 1121-bp region in the $P$. capsici A1 genome (Pcap-1 and Pcap-2), we report a PCR assay that distinguishes between $P$. capsici mating types. PCR with the primer set amplified a 997-bp amplicon and a 508-bp amplicon from A1 and A2 isolates of $P$. capsici, respectively. The 508-bp fragment possibly was a deletion of the 997-bp fragment.

In the present study, both A1 and A2 mating types of $P$. capsici were detected in a single-pepper field. Similar results have been reported in squash (Cucurbita pepo L.), pepper, processing pumpkin (Cucurbita moschata L.), and other Cucurbitaceae fields (Islam et al., 2005; Lamour and Hausbeck, 2000; Ristaino, 1990). The co-occurrence of both mating types in pepper fields increases the potential for sexual reproduction, oospore production, and genetic variation of $P$. capsici (CastroRocha et al., 2016; Li et al., 2012). The broadleaf weed, common purslane (Portulaca oleracea L.), colonized by $P$. capsici could harbor $P$. capsici during the off-season (Ploetz and Haynes, 2000), facilitating the survival of this pathogen. Crop rotation with nonhost species may be an ineffective disease management strategy in regions which A1 and A2 P. capsici mating types were colocalized with this weed. The PCR strategy described here can be applied to rapidly and accurately identify codistribution of these mating types in the field. With this assay, it may be possible to monitor the mating type effectively, and we take measures to delay the spread of the two mating types to other areas through strengthening seed transportation management, timely detection of the disease, and more timely fungicide applications. 


\section{Literature Cited}

Babadoost, M. 2000. Outbreak of phytophthora foliar blight and fruit rot in processing pumpkin fields in Illinois. Plant Dis. 84:1345.

Blair, M.W., O. Panaud, and S.R. McCouch. 1999. Inter-simple sequence repeat (ISSR) amplification for analysis of microsatellite motif frequency and fingerprinting in rice (Oryza sativa L.). Theor. Appl. Genet. 98:780-792.

Castro-Rocha, A., S. Shrestha, B. Lyon, G.L. Grimaldo-Pantoja, J.P. Flores-Marges, J. Flores-Marges, M. Aguirre-Ramírez, P. OsunaÁvila, N. Gómez-Dorantes, G. Ávila-Quezada, J. de Jesús LunaRuíz, G. Rodríguez-Alvarado, S.P. Fernández-Pavía, and K. Lamour. 2016. An initial assessment of genetic diversity for Phytophthora capsici in northern and central Mexico. Mycol. Prog. 15:1-12.

Davidson, C.R., R.B. Carroll, T.A. Evans, R.P. Mulrooney, and S.H. Kim. 2002. First report of Phytophthora capsici infecting lima bean (Phaseolus lunatus) in the mid-Atlantic region. Plant Dis. 86:1049-1052.

Erwin, D.C. and O.K. Ribeiro. 1996. Phytophthora disease worldwide. APS Press, St. Paul, MN.

Gevens, A.J., R.S. Donahoo, K.H. Lamour, and M.K. Hausbeck. 2008. Characterization of Phytophthora capsici causing foliar and pod blight of snap bean in Michigan. Plant Dis. 92:201-209.

Granke, L.L., L. Quesada-Ocampo, K.H. Lamour, and M.K. Hausbeck. 2012. Advances in research on Phytophthora capsici on vegetable crops in the United States. Plant Dis. 96:1588-1600.

Hausbeck, M.K. and K.H. Lamour. 2004. Phytophthora capsici on vegetable crops: Research progress and management challenges. Plant Dis. 88:1292-1303.

Islam, S.Z., M. Babadoost, K.N. Lambert, A. Ndeme, and H.M. Fouly. 2005. Characterization of Phytophthora capsici isolates from processing pumpkin in Illinois. Plant Dis. 89:191-197.

Judelson, H.S. 1996a. Genetic and physical variability at the mating type locus of the oomycete, Phytophthora infestans. Genetics 144:1005-1013.

Judelson, H.S. 1996b. Recent advances in the genetics of oomycete plant pathogens. Mol. Plant Microbe Interact. 9:443-449.

Judelson, H.S., L.J. Spielman, and R.C. Shattock. 1995. Genetic mapping and non-Mendelian segregation of mating type loci in the oomycete, Phytophthora infestans. Genetics 141:503-512.

Kües, U. and L.A. Casselton. 1992. Fungal mating-type genesregulators of sexual development. Mycol. Res. 96:993-1006.

Kim, K.J., S.H. Eom, S.P. Lee, H.S. Jung, S. Kamoun, and Y.S. Lee. 2005. A genetic marker associated with the A1 mating type locus in Phytophthora infestans. J. Microbiol. Biotechnol. 15:502-509.

Kim, K.J. and Y.S. Lee. 2002. Genetic DNA marker for A2 mating type in Phytophthora infestans. J. Microbiol. 40:254-259.

Ko, W.H. 1981. Reversible change of mating type in Phytophthora parasitica. Microbiology 125:451-454.

Ko, W.H. 1988. Hormonal heterothallism and homothallism in Phytophthora. Annu. Rev. Phytopathol. 26:57-73.

Lacourt, I. and J.M. Duncan. 1997. Specific detection of Phytophthora nicotianae using the polymerase chain reaction and primers based on the DNA sequence of its elicitin gene ParA1. Eur. J. Plant Pathol. 103:73-83.

Lamour, K.H. and M.K. Hausbeck. 2000. Mefenoxam insensitivity and the sexual stage of Phytophthora capsici in Michigan cucurbit fields. Phytopathology 90:396-400.

Leonian, L.H. 1922. Stem and fruit blight of pepper cause Phytophthora capsici sp. nov. Phytopathology 12:401-408.

Li, P., S. Cao, Y.L. Dai, X.L. Li, D.F. Xu, M. Guo, Y.M. Pan, and Z.M. Gao. 2012. Genetic diversity among isolates of Phytophthora capsici (Pythiaceae) in Anhui based on ISSR-PCR markers. Genet. Mol. Res. 11:4285-4296.

Papavizas, G.C., J.H. Bowers, and S.A. Johnston. 1981. Selective isolation of Phytophthora capsici from soils. Phytopathology 71:129-133.

Parra, G. and J.B. Ristaino. 2001. Resistance to mefenoxam and metalaxyl among field isolates of Phytophthora capsici causing phytophthora blight of bell pepper. Plant Dis. 85:1069-1075.

Ploetz, R.C. and J.L. Haynes. 2000. How does Phytophthora capsici survive in squash fields in southeastern Florida during the offseason? Proc. Fla. State Hortic. Soc. 113:211-215.

Qi, R.D., T. Wang, W. Zhao, P. Li, J.C. Ding, and Z.M. Gao. 2012. Activity of ten fungicides against Phytophthora capsici isolates resistant to metalaxy. J. Phytopathol. 160:717-722.

Quesada-Ocampo, L.M., D.W. Fulbright, and M.K. Hausbeck. 2009. Susceptibility of fraser fir to Phytophthora capsici. Plant Dis. 93:135-141.

Ristaino, J.B. 1990. Intraspecific variation among isolates of Phytophthora capsici from pepper and cucurbit fields in North Carolina. Phytopathology 80:1253-1259.

Satour, M.M. and E.E. Butler. 1968. Comparative morphological and physiological studies of the progenies from intraspecific matings of Phytophthora capsici. Phytopathology 58:183-192.

Savage, E.J., C.W. Clayton, J.H. Hunter, J.A. Brenneman, C. Laviola, and M.E. Gallegly. 1968. Homothallism, heterothallism and interspecific hybridization in the genus Phytophthora. Phytopathology 58:1004-1021.

Schena, L., M.M.F. Sialer, and D. Gallitelli. 2002. Molecular detection of strain L47 of Aureobasidium pullulans, a biocontrol agent of postharvest diseases. Plant Dis. 86:54-60.

Silvar, C., J.M. Duncan, D.E.L. Cooke, N.A. Williams, J. Diaz, and F. Merino. 2005. Development of specific PCR primers for identification and detection of Phytophthora capsici Leon. Eur. J. Plant Pathol. 112:43-52.

Wang, J.Y. and X.B. Zheng. 2003. Phylogenetic relationship among isolates of Phytophthora boehmeriae Sawada revealed by RAPD. Mycosystema 22:228-234.

Zietkiewicz, E., A. Rafalski, and D. Labuda. 1994. Genome fingerprinting by simple sequence repeat (SSR)-anchored polymerase chain reaction amplification. Genomics 20:176-183.

Zheng, X.B. 1997. Phytophthora and its research techniques. Chinese Agr. Press, Beijing, China. 